\title{
Analysis of Noise Level in a Campus Area: Case Study for Gazi University Maltepe Campus
}

\author{
Erman Çakıı** \\ Department of Industrial Engineering, Gazi University, Turkey \\ *Corresponding author: Erman Çakit, Department of Industrial Engineering, Gazi \\ University, Turkey, Tel: +90 312582 3809; Email: ecakit@gazi.edu.tr; ecakit@gmail.com
}

Research Article

Volume 3 Issue 4

Received Date: May 28, 2019

Published Date: July 01, 2019

DOI: $10.23880 /$ eoij-16000211

\section{Abstract}

There are several kind of sources such as cars, airplanes, vacuum cleaners, obtained as a result of technological improvement cause noise while they are working. If they are not controlled, high noise pollution will cause health problems including hearing loss, insomnia and psychological deteriorations. Noise pollution effects Gazi University Engineering Faculty Campus because of its proximity to the highways. For the purpose of assessing noise level at different points in campus area, some measurements were colllected at open and close places by using sound level meter. To capture the high noise events of campus' particular areas, noise levels were collected with a sound level meter at 16 points within the campus at three different timings (9-12 am, 12-2 pm, and 2-4 pm) over two cycles of measurements. Based on the obtained results, higher noise levels were observed during morning times and there should be taken immediate precautions to overcome noise pollution in campus area.

Keywords: Noise Mapping; Noise Pollution; Gazi University Campus Area; Sound Level Meter

\section{Introduction}

According to Florence Nightingale "Unnecessary noise is the most cruel abuse of care which can be inflicted on either the sick or the well." [1]. The word "noise" is derived from the Latin word "nausea," meaning "seasickness" or a "sensation of discomfort" and also defined as "unwanted sound", which is among the most pervasive pollutants today [2]. Noise causes a variety of mental and physical effects relevant to health problems including hearing loss, insomnia and psychological deteriorations. Recently, several studies have been conducted that highway/road traffic has become a main reason of the noise pollution and produced many adverse health effects on humans [3-15].

Colleges, universities, schools, libraries, and hospitals are considered to be a Silent Zone and require an average quiet environment. In the first instance, efforts should be made to find a site that is situated in a comparatively quiet environment. At least the site should not be close to noisy highways, railways, etc [16]. In the scope of cognitive performance, noise may affect the learning behaviors of students, and very noisy places are not suitable for teaching. Several studies have been conducted on the influence of environmental noise upon the learning and working performance [17-22]. A number of studies have showed that exposure to environmental noise can lead to a decrease in cognitive performance including difficulties in communication, impaired attention, frustration, and noise annoyance on performance [17-21].

An increase emerged in the number of private vehicles regarding the increase in the number of people (students, academicians, and administrative personnel, etc.) on the campus. On Gazi University Maltepe campus, daytime 
teaching is offered in all departments while some departments also provide evening courses. Therefore, academic programs continue during daytime and evening hours. That means daytime and evening time noise distribution collectively holds crucial value in this area. The objectives of this study are to perform the noise level measurements and determine the noise generated at Gazi University Engineering Faculty campus on the academic setting.

\section{Study Area}

The research area is the campus of the Engineering Faculty of Gazi University. The campus covers an approximately $20.000 \mathrm{~m}^{2}$ area. The Faculty includes Department of Industrial Engineering, Department of Civil Engineering, Department of Chemical Engineering, Department of Mechanical Engineering, Department of Computer Engineering, Department of Electrical Engineering, and Faculty of Architecture. Approximately 3000 students have been studying in the faculty. There is also a library located in the faculty building. The location of the study area is illustrated in Figure 1.

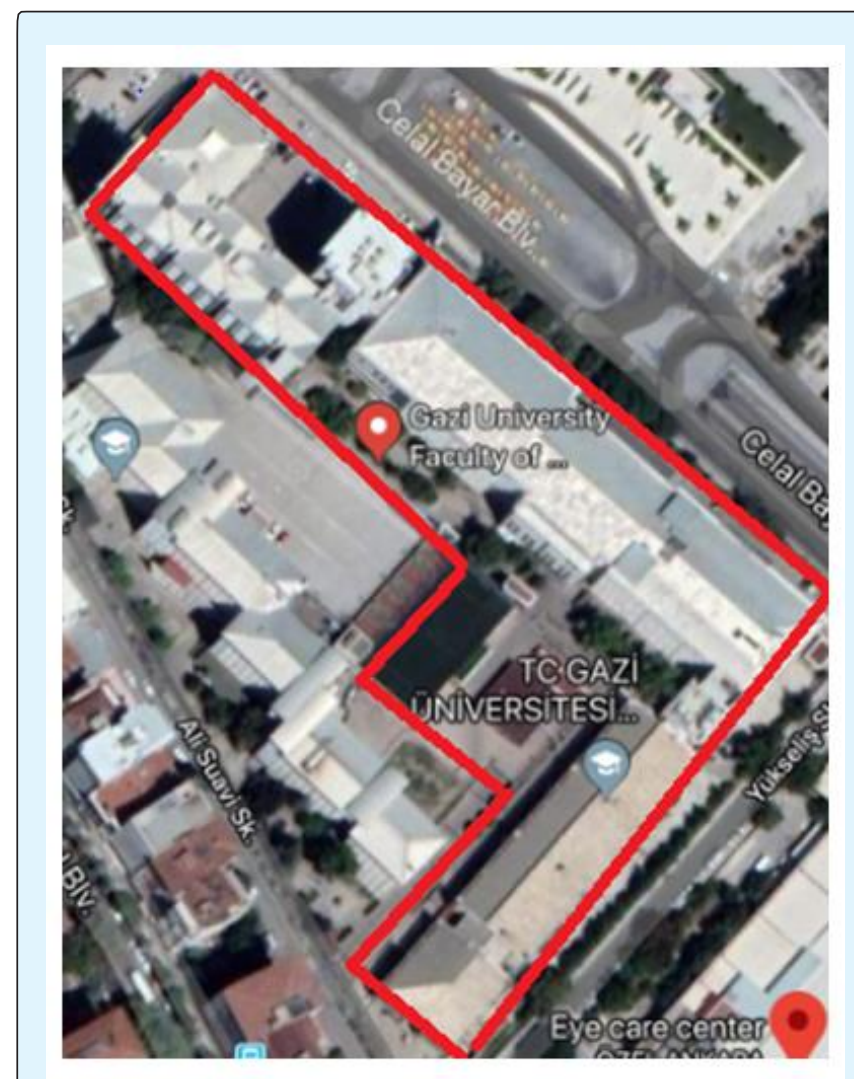

Figure 1: Location of Study Area.

\section{Methodology}

An Extech Instruments model number 407232 digital sound pressure level meters with measuring range of 30$130 \mathrm{~dB}$, accuracy of $\pm 1.5 \mathrm{~dB}$ was used for the monitoring noise levels. A total of 16 sampling collection points was taken of readings and eight timings were chosen for the study: 9 am, $10 \mathrm{am}, 11 \mathrm{am}, 12 \mathrm{pm}, 1 \mathrm{pm}, 2 \mathrm{pm}, 3 \mathrm{pm}$ and 4 $\mathrm{pm}$ to capture the high noise events of campus' particular areas (Figure 2).

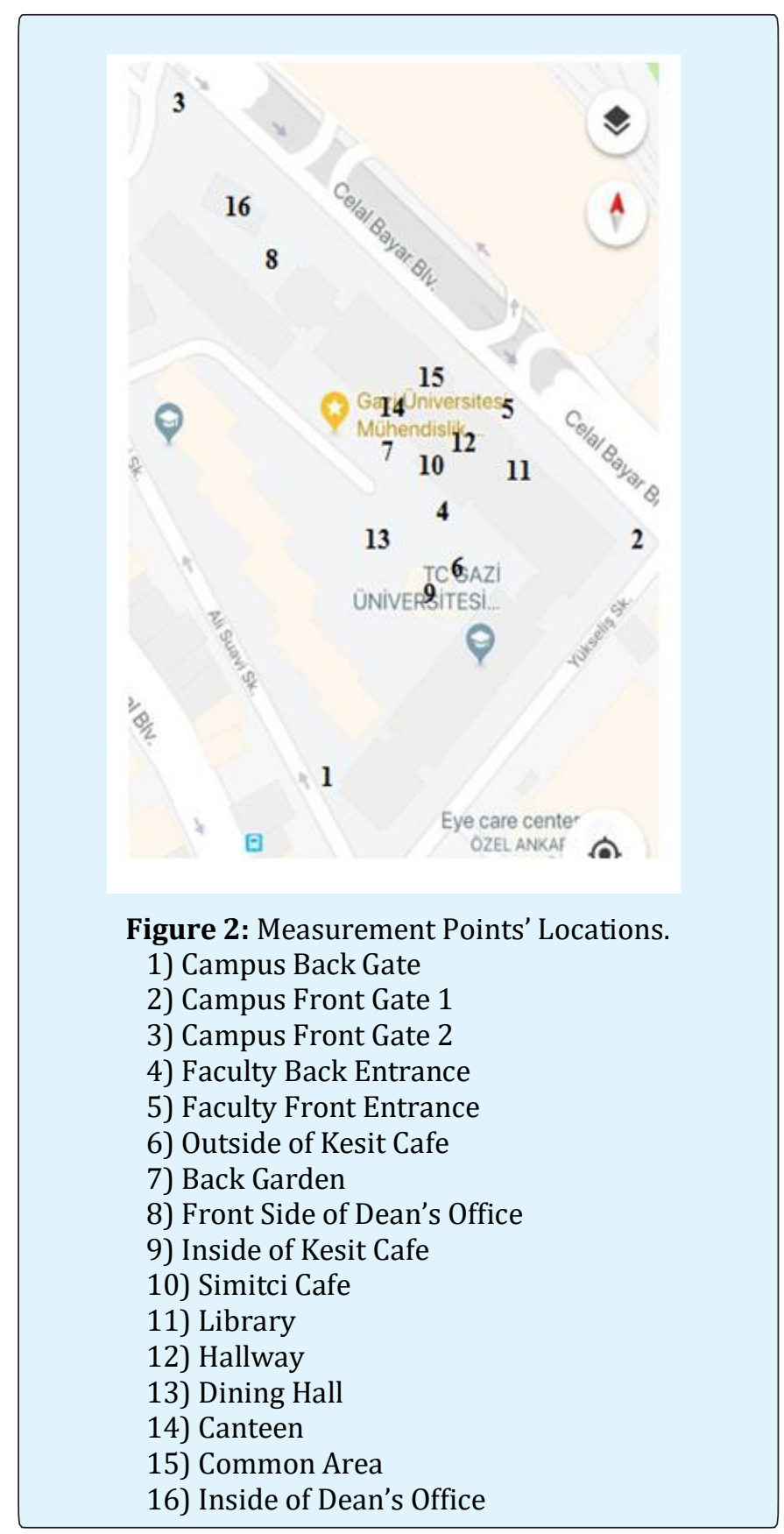




\section{Ergonomics International Journal}

In this study, the aim was to determine the dimensions of noise pollution of Engineering Faculty Campus of Gazi University. For achieving this aim, the required measurements were collected in the areas that are divided into two sections as outdoor and indoor areas (Table 1).

\begin{tabular}{|c|c|c|c|}
\hline & Outdoor Areas & & Indoor Areas \\
\hline 1 & Campus Back Gate & 9 & Inside of Kesit Cafe \\
\hline 2 & Campus Front Gate 1 & 10 & Simitci Cafe \\
\hline 3 & Campus Front Gate 2 & 11 & Library \\
\hline 4 & Faculty Back Entrance & 12 & Hallway \\
\hline 5 & Faculty Front Entrance & 13 & Dining Hall \\
\hline 6 & Outside of Kesit Cafe & 14 & Canteen \\
\hline 7 & Back Garden & 15 & Common Area \\
\hline 8 & $\begin{array}{c}\text { Front Side of Dean's } \\
\text { Office }\end{array}$ & 16 & Inside of Dean's Office \\
\hline
\end{tabular}

Table 1: Measurement Points.

\section{Results and Discussion}

The measurements collected in the open areas were analyzed by recording the maximum values with respect to every hour on Monday, which is determined the noisiest day in a week. There is a reason for measuring maximum values in this study that the values taken at random values are lower than the actual noise level and these values can be misleading. The measurements made in the closed areas were made by also recording the maximum values with respect to every hour on Monday, which is determined the noisiest day in a week. The values are shown on the table. These values are obtained during three days and their means were calculated. It can be seen that the lowest measurements were obtained in the morning hours especially at 9 am or 10 am because of the fact that the campus is not crowded at those hours due to the course schedule of students.

The reason behind the high values observed at noon hours is most of the students were at their lunch breaks and they spend most of their time in outdoors or indoors during this period. On the other hand, Library has been observed as one of the silent location in campus area. Other lowest values were measured in Dean's Office because these workplaces are dedicated to management of faculty. As the lectures are mostly over until afternoon, the lower values were obtained while comparing with sound values at noon. The results are illustrated in Figures 3 and 4.

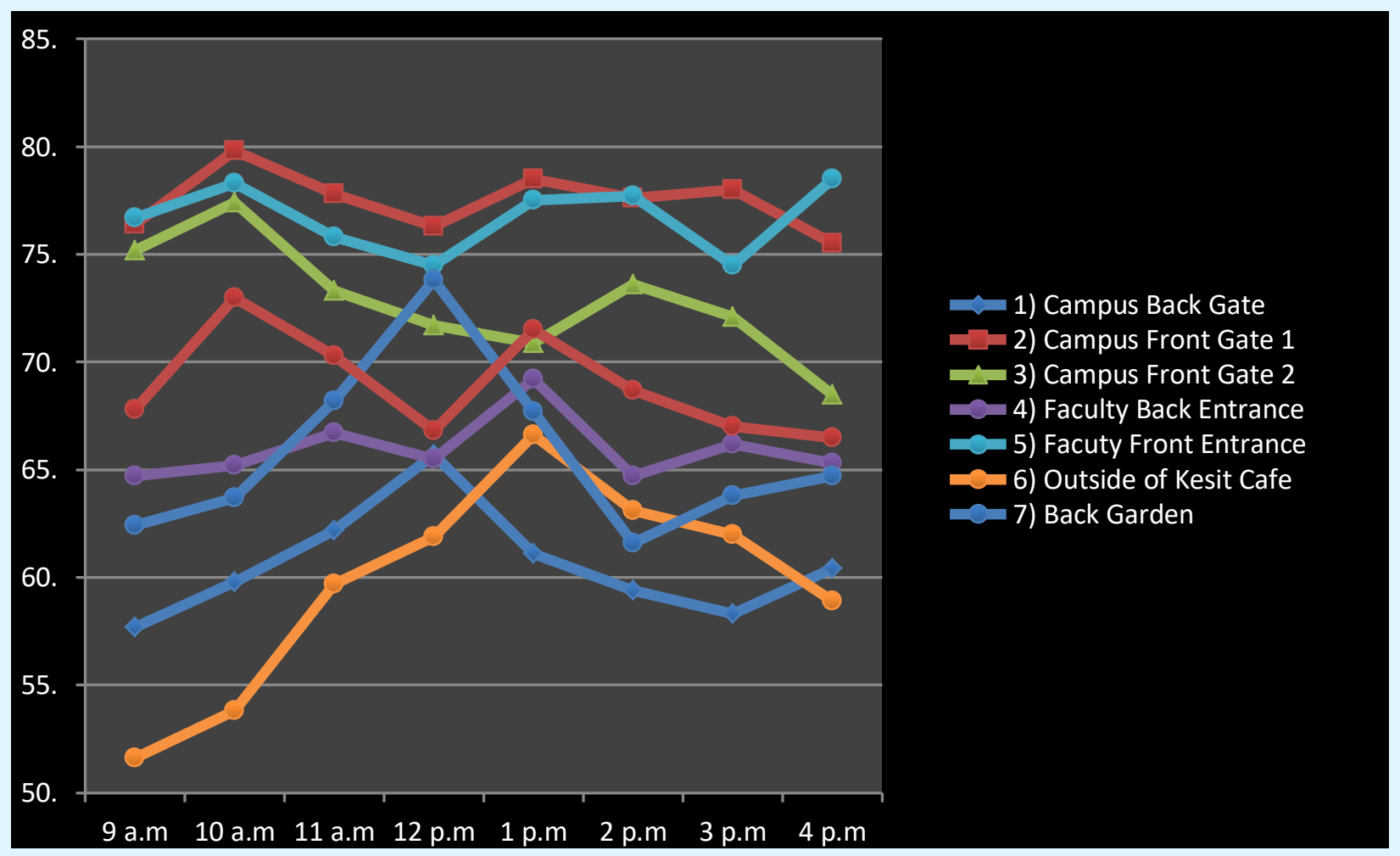

Figure 3: Results of Outdoor Places. 


\section{Ergonomics International Journal}

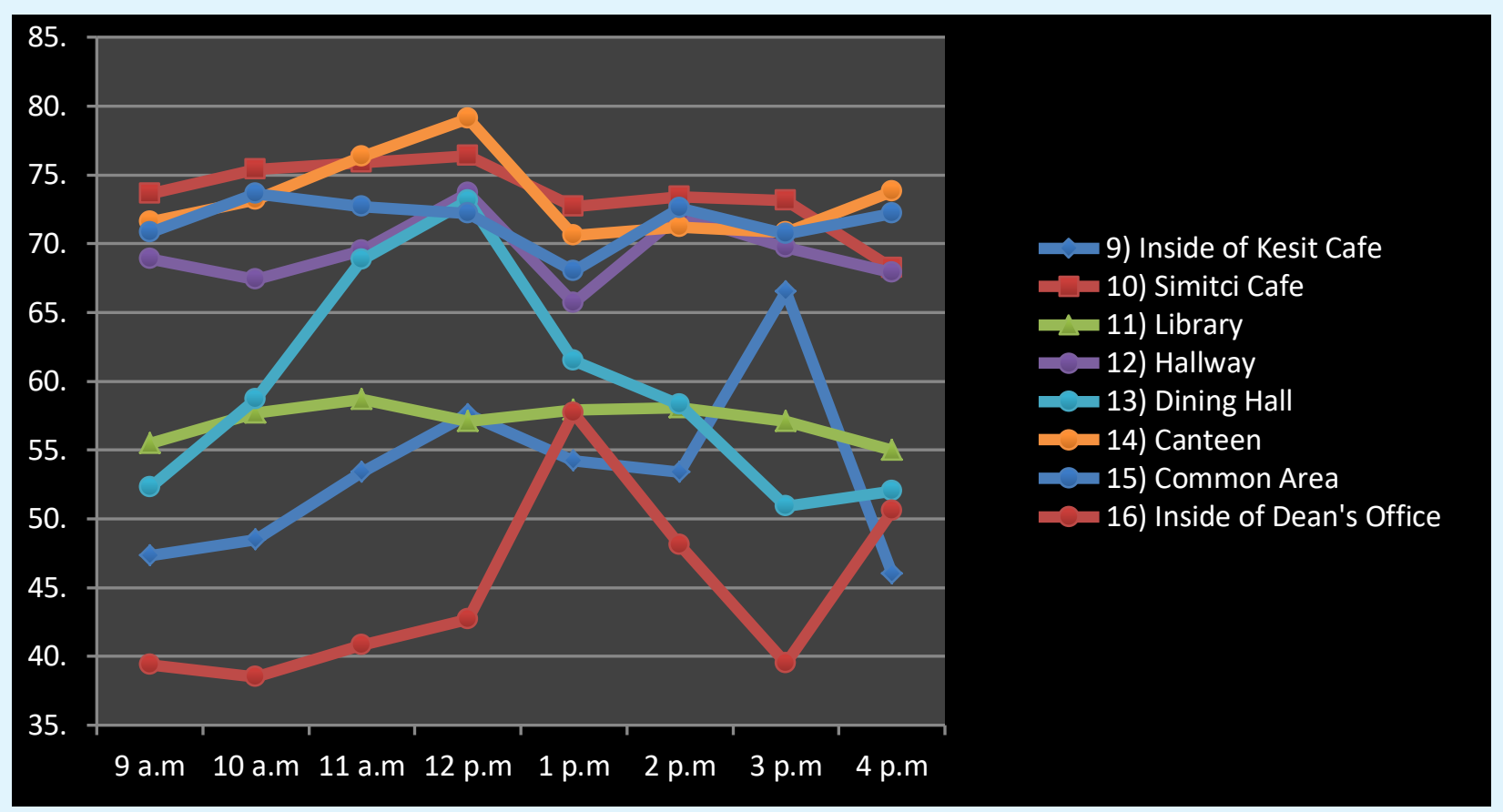

Figure 4: Results of Indoor Places.

Our results are also shown on a map too. In this format the locations which has higher voice level values are shown with red and orange and the least noisy areas are shown with light green and dark green (Figures 5a to 5i).
The buildings on the campus closer to the highway are the structures most severely exposed to noise during daytime time zone.

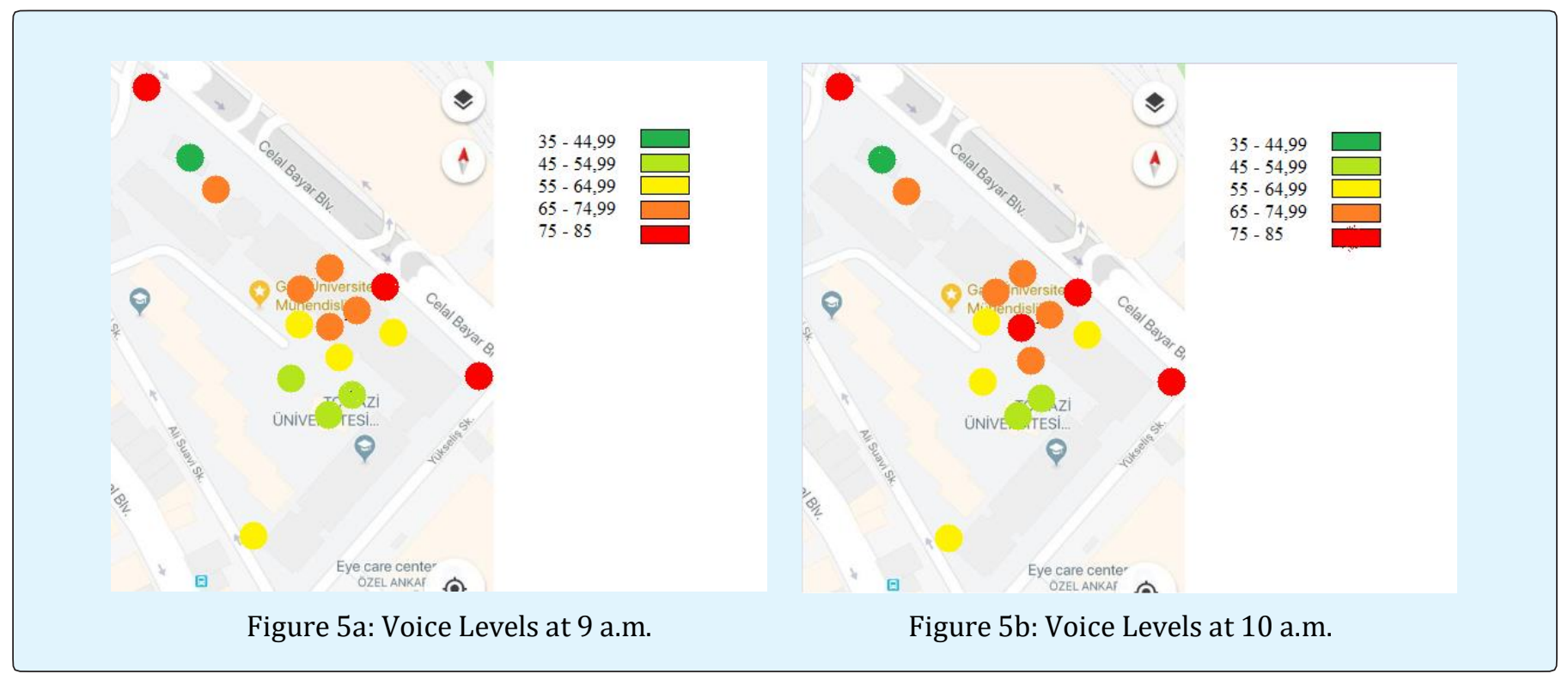


Ergonomics International Journal

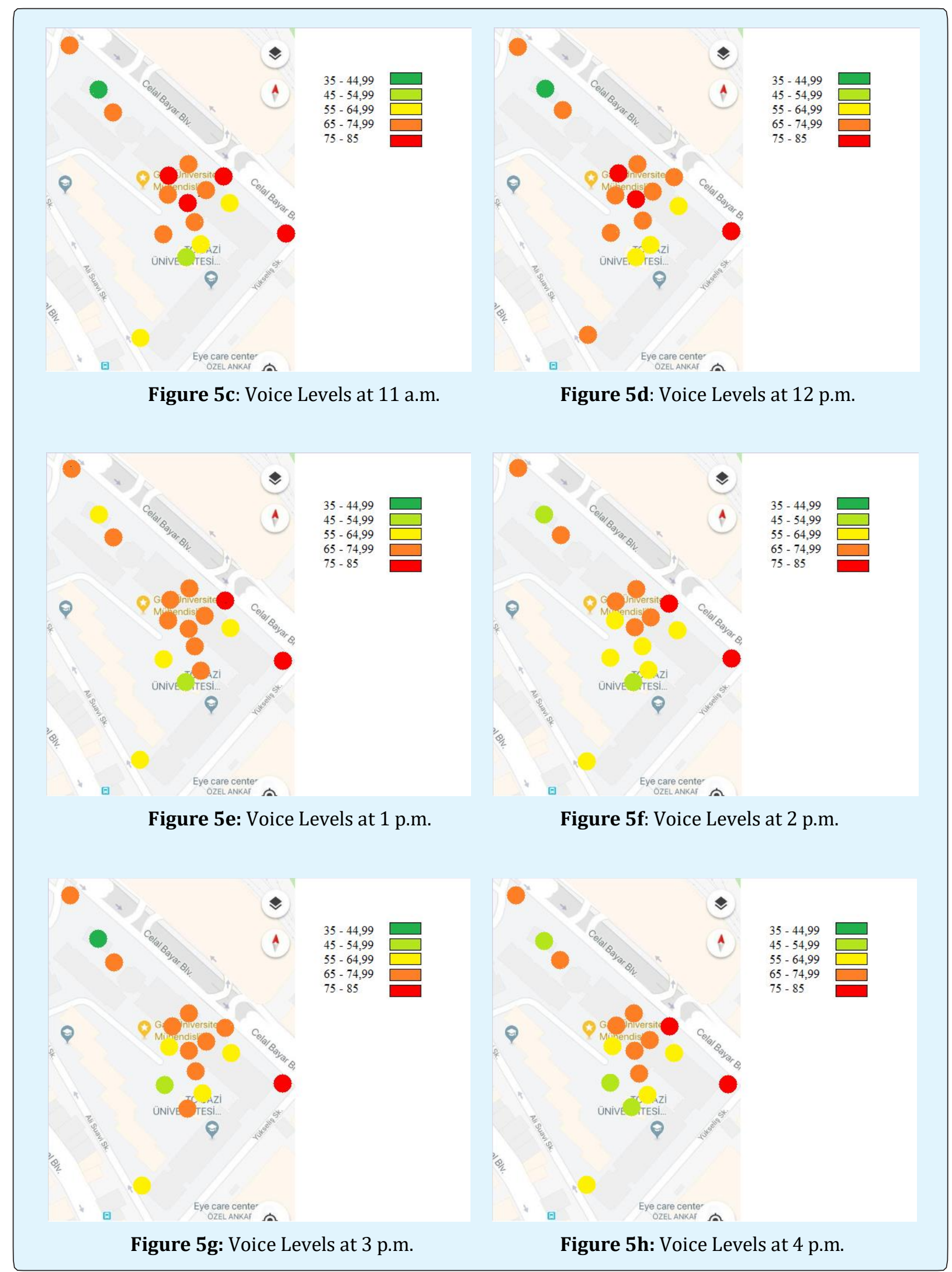




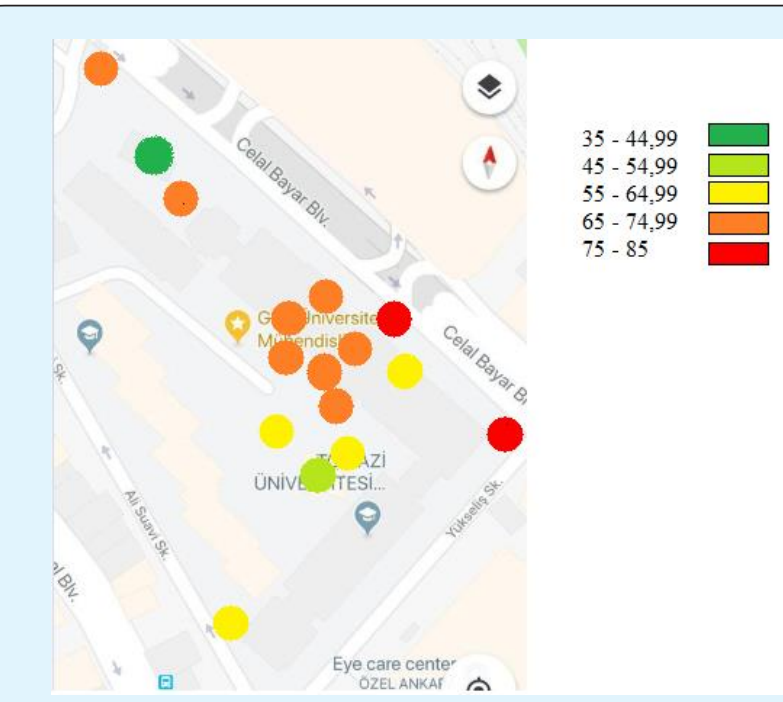

Figure 5i: Average Voice Levels Map.

Within the context of the analysis conducted in Table 3 , the results were compared with allowed values that were suggested from noise regulation and control. It is clearly seen that locations that are numbered as $1,4,6,9$, 13 and 16 are in the allowed range (Table 3). Furthermore, other locations that are not in the allowed ranges, thus these places are not optimal for sound level according to sound regulation and control values. The main reasons of this noise pollution are motorized vehicles that are running at high volume. To handle with this problem, vehicles' noise should be regulated according to the threshold values.

\begin{tabular}{|l|c|c|c|}
\hline \multicolumn{1}{|c|}{ Locations } & Mean values & Standard Deviations & Allowed Values \\
\hline 1) Campus Back Gate & 60,57 & 2,53 & 65 \\
\hline 2) Campus Front Gate 1 & 77,49 & 1,38 & 65 \\
\hline 3) Campus Front Gate 2 & 72,84 & 2,72 & 65 \\
\hline 4) Faculty Back Entrance & 65,94 & 1,49 & 70 \\
\hline 5) Faculty Front Entrance & 76,69 & 1,60 & 65 \\
\hline 6) Outside of Kesit Cafe & 59,70 & 4,93 & 65 \\
\hline 7) Back Garden & 65,74 & 4,00 & 65 \\
\hline 8) Front Side of Dean's Office & 68,95 & 2,41 & 60 \\
\hline 9) Inside of Kesit Cafe & 53,36 & 6,61 & 60 \\
\hline 10) Simitci Cafe & 73,59 & 2,58 & 45 \\
\hline 11) Library & 57,14 & 1,28 & 60 \\
\hline 12) Hallway & 69,36 & 2,57 & 60 \\
\hline 13) Dining Hall & 59,45 & 8,10 & 60 \\
\hline 14) Canteen & 73,33 & 3,02 & 60 \\
\hline 15) Common Area & 71,60 & 1,95 & 60 \\
\hline 16) Inside of Deans Office & 44,66 & 6,85 & \\
\hline
\end{tabular}

Table 3: Mean Values, Standard Deviations and Allowed Voice Levels.

To eliminate and/or minimize environmental noise pollution on the campus region, it is compulsory to take emergency measures for the current and future campus area. Some of the advised measures to take are installing sound insulation systems on the current faculty buildings on campus setting, mounting double glaze windows inside all indoor areas, and selecting suitable materials to use. 


\section{Ergonomics International Journal}

\section{Conclusion}

The population of Gazi University Maltepe campus is increasing as an effect of expanded student and staff number of current departments. As a result of increased number of students and staff, the number of vehicles also increases and this affects noise level in a negative way. In this study, the noise levels were conducted with sound level meter in Gazi University Engineering Faculty Campus. According to the obtained results, there are many places in Gazi University Engineering Faculty Campus that have noise pollution and our results help us to understand reducing the noise levels in common areas. Campus management should try to reduce the noise level to provide better educational environment for all students and lecturers. Therefore, measures should be taken in such locations to reduce the noise levels so that classrooms will not be subjected to external noise.

\section{References}

1. Nightingale F (1992) Notes on nursing: What it is, and what it is not. Lippincott Williams \& Wilkins.

2. Basner M, Babisch W, Davis A, Brink M, Clark C, et al. (2014) Auditory and non-auditory effects of noise on health. The lancet 383(9925): 1325-1332.

3. Zannin PHT, Diniz FB, Calixto A, Barbosa W (2002) Environmental noise pollution in the city of Curitiba, Brazil. Applied Acoustics 63(4): 351-358.

4. Brainard JS, Jones AP, Bateman IJ, Lowett AA (2004) Exposure to environmental urban noise pollution in Birmingham. Urban Studies 41(13): 2581-2600.

5. Counsel BD, Muer TD, Yperman I, Botteldooren D (2005) The influence of traffic dynamics on urban soundscapes. Applied Acoustics 66(2): 175-194.

6. Lebiedowska B (2005) Acoustics background and transportation noise in urbanized areas: a note on the relative classification of the city soundscape. Transportation Research Part D: Transport and Environment 10(4): 341-345.

7. Calixto A, Pulsides C, Zannin PHT (2008) Evaluation of transportation noise in urbanized areas. Archives of Acoustics 33(2): 185-199.

8. Murphy E, King EA, Rice HJ (2009) Estimating human exposure to transport noise in central Dublin, Ireland. Environment International 35(2): 298-302.
9. Zannin PHT, De Sant Ana DQ (2011) Noise mapping at different stages of a freeway redevelopment project-a case study in Brazil. Applied Acoustics 72(8): 479486.

10. Colakkadioglu D, Yucel M (2017) Modeling of TarsusAdana-Gaziantep highway-induced noise pollution within the scope of Adana city and estimated the affected population. Applied Acoustics 115: 158-165.

11. Roswall N, Nielsen OR, Ketzel M, Gammelmark A, Overvad K, et al. (2017) Long-term residential road traffic noise and NO2 exposure in relation to risk of incident myocardial infarction-a Danish cohort study. Environmental Research 156: 80-86.

12. Babisch W, Beule B, Schust M, Kersten N, Ising H (2005) Traffic noise and risk of myocardial infarction. Epidemiology 16(1): 33-40.

13. La Torre G, Moscato U, La Torre F, Ballini P, Marchi S, et al. (2007) Environmental noise exposure and population health: a cross-sectional study in the province of Rome. Journal of Public Health 15: 339344.

14. Moudon AN (2009) Real noise from the urban environment: how ambient community noise affects health and what can be done about it. Am J Prev Med $37(2): 167-171$.

15. WHO (2011) Burden of disease from environmental noise: Quantification of healthy life years lost in Europe, WHO Regional Office for Europe, World Health Organization.

16. Thattai D, Sudarsan JS, Sathyanathan R, Ramasamy V (2017) Analysis of noise pollution level in a University campus in South India. In IOP Conference Series: Earth and Environmental Science IOP Publishing 80(1): 012053.

17. Pheng HS, Yean TS, Lye KH, Ismail AIM, Kassim S (2006) Modeling noise levels in USM penang campus. In Proceedings $2^{\text {nd }}$ IMT-GT regional conference on mathematics, statistics \& applications. University Sains Malaysia, Penang.

18. Thakur GS (2006) A study of noise around an educational institutional area. Journal of Environmental Science \& Engineering 48(1): 35-38. 


\section{Ergonomics International Journal}

19. Zannin PH, Zwirtes DP (2009) Evaluation of the acoustic performance of classrooms in public schools. Applied Acoustics 70(4): 626-635.

20. Goswami S, Nayak SK, Pradhan AC, Dey SK (2011) A study on traffic noise of two campuses of university, Balasore, India. Journal of Environmental Biology 32(1): 105-109.

21. Xie H, Kang J, Tompsett, R (2011) The impacts of environmental noise on the academic achievements of secondary school students in Greater London. Applied Acoustics 72(8): 551-555.

22. Tzivian L, Jakisch M, Winkler A, Weimar C, Hennig F, et al. (2017) Associations of long term exposure to air pollution and road traffic noise with cognitive function-an analysis of effect measure modification. Environmental International 103: 30-38. 